\title{
TUBERCULOSIS
}

\section{Evaluación de la reacción en cadena de polimerasa en tiempo real (PCR-RT), interferón gamma, adenosín deaminasa e inmunoglobulina A para el diagnóstico de tuberculosis pleural}

\section{Assessment of real-time polymerase chain reaction (RT-PCR), interferon gamma, adenosine deaminase, and immunoglobulin A for diagnosing pleural tuberculosis}

María Fernanda Buitrago Rodríguez, MD ${ }^{(1)}$; Olga Milena García, MD(2)

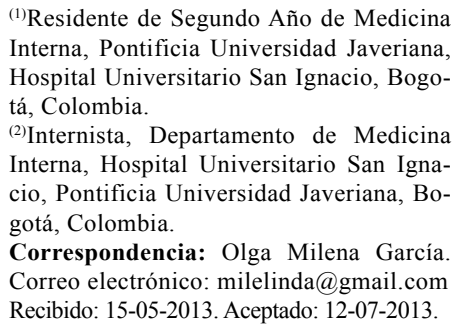

${ }^{(1)}$ Residente de Segundo Año de Medicina Interna, Pontificia Universidad Javeriana, Hospital Universitario San Ignacio, Bogotá, Colombia.

${ }^{(2)}$ Internista, Departamento de Medicina Interna, Hospital Universitario San Ignacio, Pontificia Universidad Javeriana, Bogotá, Colombia.

Correspondencia: Olga Milena García. Correo electrónico: milelinda@gmail.com Recibido: 15-05-2013. Aceptado: 12-07-2013.

\begin{abstract}
Referencia
Kalantri Y, Hemvani N, et al. Evaluation of real-time polymerase chain reaction, interferon-gamma, adenosine deaminase, and immunoglobulin A for the efficient diagnosis of pleural tuberculosis. Int J Infect Dis. 2011;15:226-231.

\section{Pregunta}

¿Es útil la combinación de pruebas diagnósticas como reacción en cadena de polimerasa en tiempo real (PCR-RT), interferón gamma (INF- $\gamma$ ), adenosín deaminasa (ADA) e inmunoglobulina A (IgA) en el diagnóstico de tuberculosis (TB) pleural?
\end{abstract}

\section{Diseño}

Estudio de pruebas diagnósticas. Evaluación de las características operativas de siete pruebas diagnósticas para TB pleural. Posterior a determinar su eficacia individual se evaluaron las características y la eficacia cuando se combinaban diferentes métodos.

\section{Lugar}

Hospital y Centro de investigación Choithram, Indore, India.

\section{Pacientes}

204 pacientes remitidos entre febrero de 2008 y octubre de 2009, con diagnóstico de derrame pleural.

\section{Descripción de las pruebas}

Para INF- $\gamma$ e IgA se utilizó técnica de ELISA; el ADA se midió por ensayo colorimétrico y la PCR-RT se realizó utilizando una secuencia de 16sRNA. Adicionalmente, se tomaron coloración ácido-alcohol resistente y cultivo para TB en muestras de líquido pleural y se realizó biopsia pleural.

\section{Diagnóstico}

Los pacientes se dividieron tres grupos: 
1. TB confirmada por pruebas convencionales: tinción ácido-alcohol resistente positiva, cultivo en líquido pleural para Mycobacterium tuberculosis positivo o biopsia pleural con granulomas caseificantes.

2. TB probable, basada en síntomas y signos clínicos, o con recuento linfocitario aumentado en el líquido pleural y con respuesta a medicamentos anti-TB indicados de forma empírica y con exclusión de otros diagnósticos.

3. Derrame pleural de etiología diferente a TB (malignidad, infección por gérmenes no TB, etc.)

\section{Desenlaces}

Sensibilidad, especificidad, valores predictivos positivo y negativo, y curvas ROC para cada prueba.

\section{Resultados principales}

El estudio con INF- $\gamma$ mostró la mayor sensibilidad, tanto en pacientes con TB confirmada como en TB probable, con valores de $98 \%$ y $76 \%$, respectivamente; los valores de especificidad fueron del $96 \%$ tanto en el grupo de TB probable como confirmada.

La sensibilidad del ADA fue mayor que la de coloración ácido-alcohol resistente, cultivo y biopsia, pero inferior al INF- $\gamma$, con valores del $92 \%$ en el grupo de TB confirmada y del $73 \%$ en TB probable.
La sensibilidad de la PCR-RT fue significativamente mayor que la de coloración, cultivo y biopsia pleural; sin embargo, inferior a la de INF- $\gamma$, con valores del $80 \%$ en el grupo de TB confirmada y del $57,7 \%$ en el de TB probable, aunque es importante destacar los valores de especificidad de este método, que son del $98 \%$ tanto para TB confirmada como probable.

En cuanto a la combinación de métodos, la de INF- $\gamma$ y ADA alcanzaron la más alta sensibilidad, con un valor del $92 \%$ y especificidad del $100 \%$ en el grupo de TB confirmada, mientras que para la TB probable fue de $65,4 \%$ y $100 \%$, respectivamente. Los otros datos combinados se presentan en la tabla.

\section{Conclusión}

El INF- $\gamma$ mostró la más alta sensibilidad como prueba individual. La combinación de INF- $\gamma$ y ADA fue la de más alta sensibilidad y especificidad.

\section{Comentario}

Tradicionalmente el diagnóstico de TB pleural se ha basado en pruebas convencionales como la coloración para bacilos ácido-alcohol resistentes, el cultivo para Mycobacterium tuberculosis y la biopsia pleural; sin embargo, estos estudios no siempre permiten hacer el diagnóstico (2).

El estudio de Kalantri y colaboradores, investigó la combinación de pruebas diagnósticas para el

Tabla. Evaluación de las características operativas de las combinaciones de pruebas diagnósticas.

\begin{tabular}{|c|c|c|c|c|c|c|}
\hline Grupo de pacientes & INF-y + ADA & INF-y + RT-PCR & INF-y + IgA & RT-PCR+ ADA & $A D A+\lg A$ & RT-PCR+ IgA \\
\hline \multicolumn{7}{|l|}{ TB confirmada } \\
\hline Sensibilidad & $92 \%$ & $80 \%$ & $70 \%$ & $78 \%$ & $66 \%$ & $68 \%$ \\
\hline Especificidad & $100 \%$ & $100 \%$ & $96 \%$ & $100 \%$ & $96 \%$ & $100 \%$ \\
\hline VPP & $100 \%$ & $100 \%$ & $94,6 \%$ & $100 \%$ & $94,3 \%$ & $100 \%$ \\
\hline VPN & $92,5 \%$ & $83 \%$ & $76,2 \%$ & $82 \%$ & $73,8 \%$ & $77,5 \%$ \\
\hline \multicolumn{7}{|l|}{ TB probable } \\
\hline Sensibilidad & $65,4 \%$ & $38,5 \%$ & $57,6 \%$ & $36,5 \%$ & $37,5 \%$ & $26,9 \%$ \\
\hline Especificidad & $100 \%$ & $100 \%$ & $96 \%$ & $100 \%$ & $96 \%$ & $100 \%$ \\
\hline VPP & $100 \%$ & $100 \%$ & $96,8 \%$ & $100 \%$ & $94,6 \%$ & $100 \%$ \\
\hline VPN & $58,1 \%$ & $43,9 \%$ & $52,2 \%$ & $43,1 \%$ & $64,7 \%$ & $39,7 \%$ \\
\hline
\end{tabular}


estudio de TB, siendo la combinación de estas superior a los métodos convencionales. La combinación con mayor especificidad y sensibilidad fue la de INF- $\gamma$ y ADA.

INF- $\gamma$ fue la prueba individual con mayor sensibilidad y alta especificidad corroborando hallazgos previos del estudio de Liang y colaboradores (1) y demostrando su papel en el diagnóstico actual de la TB. Es importante tener en cuenta que los resultados de esta prueba deben ser interpretados a la luz de la clínica del paciente. Adicionalmente, el uso rutinario de esta prueba dependerá de los recursos económicos disponibles.

\section{Bibliografía}

1. Liang J, Shi HZ, et al. Diagnostic value of interferon- $\gamma$ in tuberculosis pleuresy. A metaanalisis. CHEST. 2007;131:1133-41.

2. Krenke R, Korczynski P. Use of pleural fluid levels of adenosine deaminase and interferon gamma in the diagnosis of tuberculous pleuritis. Curr Opin Pulm Med. 2010;16:367-75. 